\title{
Selection of Maize Genotypes with Tolerance to Osmotic Stress Associated with Salinity
}

\author{
Mónica B. Collado*, Mónica B. Aulicino, Miguel J. Arturi, María del C. Molina \\ Instituto Fitotécnico de Santa Catalina, Facultad de Ciencias Agrarias y Forestales, Universidad Nacional de La \\ Plata, Provincia de Buenos Aires, Argentina, CONICET \\ Email: *mcmgen@yahoo.com
}

Received 8 January 2016; accepted 19 February 2016; published 22 February 2016

Copyright (C) 2016 by authors and Scientific Research Publishing Inc.

This work is licensed under the Creative Commons Attribution International License (CC BY).

http://creativecommons.org/licenses/by/4.0/

(c) (i) Open Access

\section{Abstract}

Thirteen different inbred lines in relation to the type of grain and life cycles were characterized by testing for osmotic stress associated with salinity. The identification of tolerant genotypes would be an effective strategy to overcome the saline stress. Osmotic stress reduces immediately the expansion of the roots and young leaves which determine a reduction in the size of the plant. A completely randomized design was adopted to test seedlings under controlled conditions of light and temperature. Two treatments were used: $0 \mathrm{mM} \mathrm{NaCl}$ (as control) and $100 \mathrm{mM} \mathrm{NaCl}$. After 15 days of complete salinization, the seedlings were harvested and several morphological traits were measured. The morphological traits of growth were leaf growth (Ar1, Ar2, Ar3 and Ar4), dry masses of shoot and root (SDM and RDM, respectively). Also, traits associated with water economy were registered: leaf water loss (LWL) and relative water content (RWC). The morphological traits were expressed in relative terms, while the traits associated with the economy of water were expressed in absolute terms. Uni and multivariate techniques were applied to identify genotypes with divergent behaviors to osmotic stress tolerance. Also, a Tolerance Index was employed to identify superior genotypes. Four clusters were obtained after applying a Cluster Analysis and Principal Component Analysis (PCA). The genotypes were compared to each other with a test of DMS. The results obtained with different statistical techniques converged. Some variables presented a differential weight classification of genotypes. The morphological traits like RDM, SDM, Ar3, Ar4 and Ar5 were the most discriminating. Tolerance Index allowed to classify genotypes, thus SC2 and AD3 lines were that reached highest value of the index and therefore would be tolerant lines, while AF3 and LP3 had a low index and were seen as sensible.

\section{Keywords}

Maize, Salinity, Osmotic Stress Tolerance, Selection Index

\footnotetext{
"Corresponding author.
}

How to cite this paper: Collado, M.B., Aulicino, M.B., Arturi, M.J. and del C. Molina, M. (2016) Selection of Maize Genotypes with Tolerance to Osmotic Stress Associated with Salinity. Agricultural Sciences, 7, 82-92. 


\section{Introduction}

Saline soils are abiotic factors with great negative effect exerted on world agriculture [1]. The identification of crops tolerant would be an effective strategy to overcome the saline stress. Salinity affects some physiological and biochemical processes of the plants and reduces significantly the yield. Photosynthesis is the most important process affected by salinity; this may be due, among other things, to the closure of the stomata. Besides, it reduces the ability of the plant to use water, which causes a decrease in the rate of growth [2]-[4].

A two-phase model to explain the inhibition of the growth under salinity conditions was proposes. The first phase is known like osmotic phase, where the decrease of the water potential of the soils is produced by the salt accumulation [5].

Osmotic effects are observed rapidly after the salt application and continue during all the exhibition time determining the inhibition of the expansion and cellular division, as well as the stomata closure [3] [6] [7].

The second stage is called an ionic phase where the inhibition is due to a rapid increase of the salt in the apoplast or the cytoplasm when the vacuoles cannot accumulate any more salt ions. The ionic effects cause an early senescence of the old leaves, with symptoms of toxicity (chlorosis and necrosis) [8] [9].

In addition, the high concentration of $\mathrm{Na}^{+}$affects the synthesis of proteins and enzyme activity [10]. The reduction of growth by salinity would be mainly due to the osmotic effects rather than the ionic [6]. However, it is also possible that ionic effects arise in the first phase and the osmotic effects persist in the second phase [11] [12]. Plants have developed three mechanisms to tolerate salt stress. The first one is that of tolerance to osmotic stress (related to the first phase of reduction of the growth) and the other two mechanisms (associated with the ionic stress) are the exclusion of $\mathrm{Na}^{+}$from the leaves and the tolerance of the tissues [6]. In wheat and other cereals, it will appear that salinity tolerance is associated with the exclusion of $\mathrm{Na}^{+}$[13]. Maize is considered as a crop moderately sensitive to salinity [14] and has been characterized as a plant that presents the exclusion of $\mathrm{Na}^{+}$ as a method of tolerance [15]. However, it is believed that the two other mechanisms will also be important in determining the tolerance [6].

Osmotic stress reduces immediately the expansion of the roots and young leaves which determine a reduction in the size of the plant. This reduction can be attributed to a decrease in the rate of growth, including cell division and cell expansion, while the duration of growth will not be affected [7]. Osmotic phase could stay several hours or days before the $\mathrm{Na}^{+}$concentration reaches toxic levels. In this way, daily measurements of the length of the young leaves would be a good indicator of osmotic stress. Plants tolerance to osmotic stress would be that keeps the rate of growth during the first days of exposure to salinity [6]. This response can be seen as an adaptive feature that reduces the loss of water by transpiration or as a reduction in stomatal efficiency by partial or total closure of the stomata which affects photosynthesis [7]. Thus the improvement of the tolerance to the osmotic stress could involve two opposing strategies. The first of these is to select plants with lower leaf area which will avoid water stress, and is associated with improvement of stomatal efficiency. While the second strategy is to select plants that keep the leaf area and the interception of light, which will be related to the improvement of the efficiency of absorption of water from the roots [7].

The aims of this study were: (a) to assess the effects of salinity on growth and water economy traits in seedlings of maize, as a way to identify the presence of osmotic tolerance and b) to explore the presence of genetic variability for such a mechanism; with the purpose of identifying genotypes of contrasting behavior useful for gene effects' studies and for breeding programs.

\section{Materials and Methods}

\subsection{Plant Material}

We selected 13 maize inbred lines (genotypes) that represent a wide range of racial origins, maturity and grain type (Table 1).

\subsection{Hydroponic System}

Seeds from the different genotypes were sterilized in the surface with 1\% sodium hypochlorite solution for 5 minutes before experimentation, and then rinsed with distilled water. Pre-germinated caryopses were transferred to pots containing perlite. These pots were put in trays with 1/4 strength Hoagland's solution. The full-strength nutrient solution had the following composition: in mol·m ${ }^{-3}, \mathrm{Ca}(\mathrm{NO})_{2}, 2.5 ; \mathrm{KH}_{2} \mathrm{PO}_{4}, 0.1 ; \mathrm{K}_{2} \mathrm{SO}_{4}, 0.5$; 
Table 1. Food and Agriculture Organization of the United Nations (FAO) maturity (Short: minor than 500; Medium: between 500 to 700; Large: major than 700) and type and color grain (O: Orange, Y: Yellow, F: Flint; D: Dent) of the 13 evaluated genotypes.

\begin{tabular}{cccc}
\hline Genotype & Color grain & Type of grain & Maturity \\
\hline AD3 & O & F & Large \\
AFE & O & F & Large \\
B73 & Y & D & Short \\
F2 & O & F & Short \\
F564 & O & F & Short \\
Gaspé & O & F & Medium \\
LP3 & O & F & Medium \\
Mo17 & Y & D & Medium \\
P21 & O & F & Short \\
SC2 & O & F & Short \\
SC75 & Y & F & Short \\
SC75m & Y & F & Large \\
WXEb & O & F & \\
\hline
\end{tabular}

$\mathrm{MgSO}_{4}, 0.6 ; \mathrm{CaCl}_{2}, 5$; in mmol.m ${ }^{-3} \mathrm{H}_{3} \mathrm{BO}_{4}, \mathrm{I} ; \mathrm{MnSO}_{4}, 2 ; \mathrm{ZnSO}_{4}, 0.5 ; \mathrm{CuSO}_{4}, 0.3 ; \mathrm{NH}_{4} \mathrm{MO}_{7} \mathrm{O}_{24}, 0.005$; Fe-EDTA, 200. Daily increments of $1 / 4$ of concentration in the nutrient solution were made to reach the complete solution; the $\mathrm{pH}$ solution was maintained at 6 .The solutions were renewed every three days.

\subsection{Treatments}

The experiment was carried out in a controlled environment room at $25^{\circ} \mathrm{C}$, with $16 \mathrm{~h}$ day length. A completely randomized design with three replicates was adopted. Each replicate was a plot with three plants (experimental unit).Three plots per accession were assigned to each treatment. Two treatments were used: $0 \mathrm{mM} \mathrm{NaCl}$ (as control) and $100 \mathrm{mM} \mathrm{NaCl}$ [16] [17]. The final concentration was reached by a gradual increment of $25 \mathrm{mM}$ $\mathrm{NaCl}$ every day [18]. After 15 days of complete salinization, the seedlings were harvested.

\subsection{Measurement}

Leaf Growth Measurement after completing the salinity both the length and width of $4^{\text {th }}$ and $6^{\text {th }}$ leaf were measured every 2 days (4 measurements in total: Ar1 to Ar4). Also, the area of the blade on each measurement was estimated [19].

Length Root (LR) measured in $\mathrm{cm}$.

Shoot Dry Mass (SDM) and Root Dry Mass (RDM), were obtained after drying in an oven at $70^{\circ} \mathrm{C}$ to constant weight.

Relative water content (RWC) was determined on cut leaves in pieces [20]. Applying the following formula:

$$
\mathrm{RWC}(\%):(\mathrm{FW}-\mathrm{DW}) /[(\mathrm{TW}-\mathrm{DW}) * 100]
$$

where FW = fresh weight, obtained immediately after the harvest; DW = dry weight, obtained by drying the sample in an oven until constant weight and TW = weight of turgor, determined then to rehydrate the bits of leaves for 2 hours.

Leaf Water Loss (LWL) The fresh weights of pieces of leaf were recorded (W1), then these pieces were left to evaporate under ambient conditions for 2 hours then turned to weigh (W2). The following formula was used: 


$$
L W L=(W 1-W 2) / W 1 * 100[21] .
$$

Stability of membrane (IE) was determined on the $6^{\circ}$ leaf with the use of a conductivity meter (Consort C931) [21]. A piece of leaf was cut, weight and washed with distilled water, then these pieces were placed in a tube with $10 \mathrm{ml}$ of distilled water and left to incubate at $10^{\circ} \mathrm{C}$ in cooled incubator for a period of 24 hours [22]. After incubation, it was left to stabilize the sample to room temperature and the conductivity of the solution (M1) was measured. Then, the samples were autoclaved by 15 minutes to kill the tissue, were left at room temperature. The conductivity of solutions was again measured (M2). The stability index was obtained from the following formula:

$$
I E=M 1 / M 2 * 100
$$

The morphological traits of growth (Ar1, Ar2, Ar3 and Ar4, SDM and RDM) were expressed in relative terms as a ratio between the measurements in salt over the same measurement in the control without salt, while the traits associated with the economy of water: RWC, LWL and IE were expressed in absolute terms.

Tolerance index was estimated for each trait that showed significant differences in the ANOVA. The variables expressed in relative values were divided by the best value obtained, in such a way that the best behavior in salt was corresponded with a value equal to 1 while the other values were less than 1 . Summarized these values a tolerance index for each genotype was calculated.

\subsection{Statistical Analysis}

A DCA with an unequal number of repetitions was used. Data were subjected to analysis of variance and the Fisher's least significant difference (LSD) was used for the comparison of means [23]. Numerical taxonomy techniques were applied to classify the genotypes across quantitative traits measured only in salt conditions [24]. A basic data matrix was standardized due to different measurement units of the variables. We performed a cluster analysis, based on two distance coefficients: Average taxonomic distance and Manhattan distance [25]. Subsequently the UPGMA linkage method was applied on both matrices, using NTSYS-pc program [26]. Cophenetic correlation coefficient was used to select the methodology to produce less distortion. Only the dendogram reached the highest cophenetic correlation coefficient value (CCC) was presented. The cut of the groups was performed in a subjective way, using a distance coefficient major to 1 . A one way analysis of variance and comparison between means, using LSD test $(p<0.05)$, were applied to probe differences between clusters [23]. Principal component analysis (PCA) was performed to classify genotypes in a tri-dimensional graph and to identify the importance of the traits and the variance percentage explained by each one of the three first principal components [24].

\section{Results}

The measured traits showed the presence of significant differences for genotypes, except for the character Ar1 that did not show significant differences (Table 2).

The application of LSD Test revealed the presence of differences in the behavior of the tested genotypes. Comparison for LR identified the genotypes: P21, AD3, Gaspe and AFE as those of major growth of root while the genotypes LP3, F2 and B73 showed a less radicular growth (Figure 1(a)). The frequencies distribution of the genotypes for the SDM and RDM showed a great similarity. In addition the genotypes WXEb, SC2 and AD3 presented the best behaviors and differ significantly from LP3 and SC75m (Figure 1(b) and Figure 1(c)). The measurement of the LWL and the RWC are simple, quick and easy ways to have an idea of the water status of the plant. The genotypes evaluated for LWL showed statistically different behavior (Table 3, Figure 1(d)). AFE, SC2, AD3 and SC75m genotypes had the smallest loss of water than LP3 and B73. For RWC, F564, Gaspé and SC75 genotypes had higher water content and differed statistically from P21, SC2, and WXEb with the lower water content (Figure 1(e)). The evaluated genotypes showed significant differences for IE. The AFE, F2 and SC75m genotypes were those who suffered most damage of membrane, while Mo17, AD3 and Gaspé presented the lowest one (Figure $1(\mathrm{f})$ ).

Evaluation of the leaf area measured on the leaf $4^{\text {th }}$ (Figure 2) showed that the $2^{\text {nd }}$ measurement was the most affected by salinity, making values less than 1. P21, AD3, Mo17, Gaspe and F564 genotypes increased the range of growth along all measurements, while the remaining genotypes stabilized or decreased in the $4^{\text {th }}$ measurement 


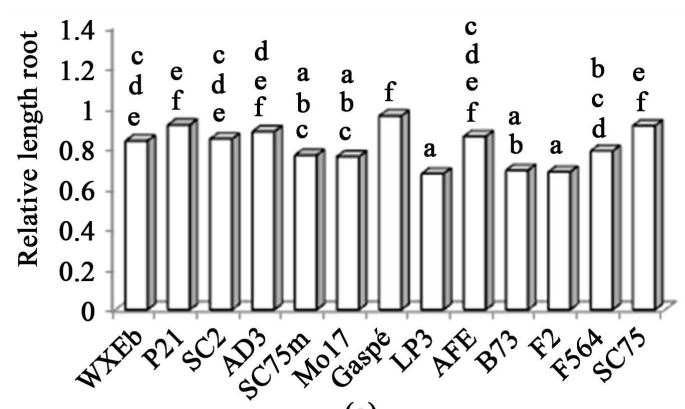

(a)

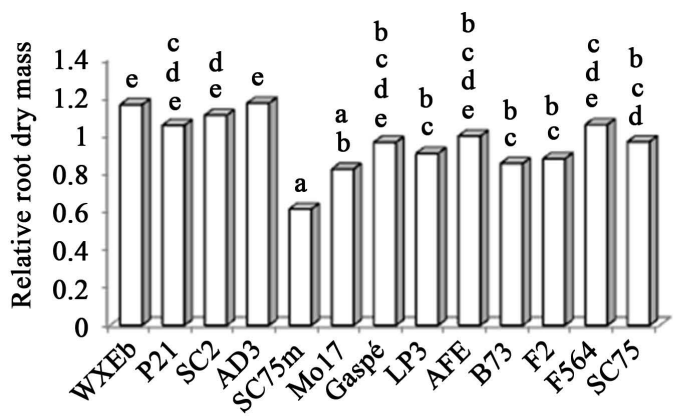

(c)

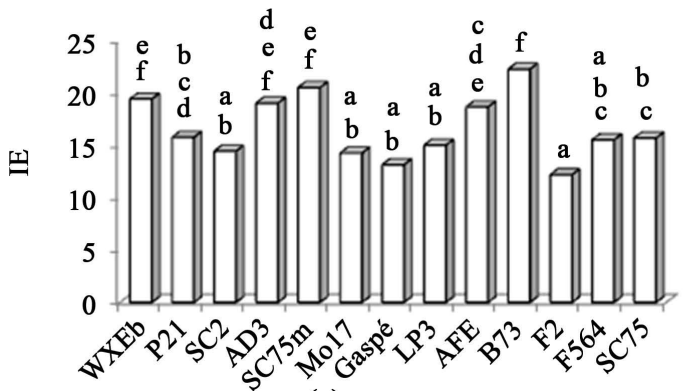

(e)

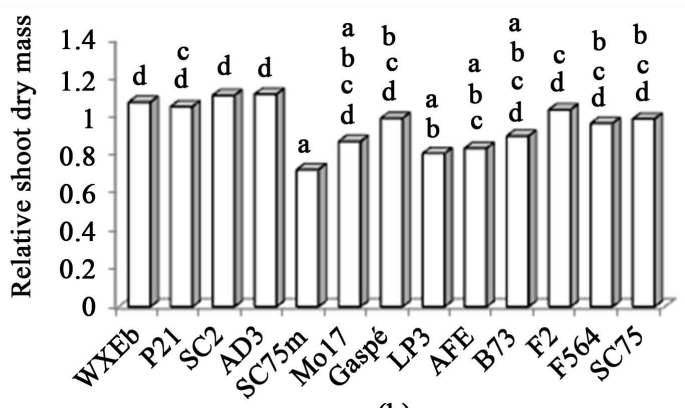

(b)

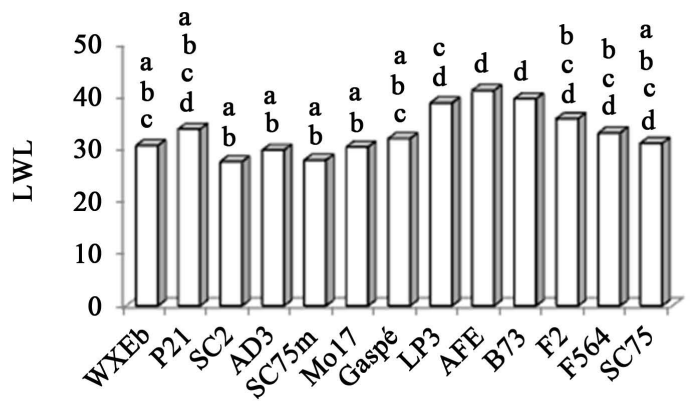

(d)

Figure 1. Least significant difference $(p<0.05)$ for the comparison between maize genotypes exposed during two weeks to $0 \mathrm{mM}$ (control) and $100 \mathrm{mM}$ of $\mathrm{NaCl}$ doses. Relative's values were calculated as the ratio between the value measured in salt and the value measured without salt, control. (a) Relative Length Root; (b) Relative shoot dry mass; (c) Relative root dry mass; (d) Leaf water loss (LWL); (e) Stability of membrane (IE).

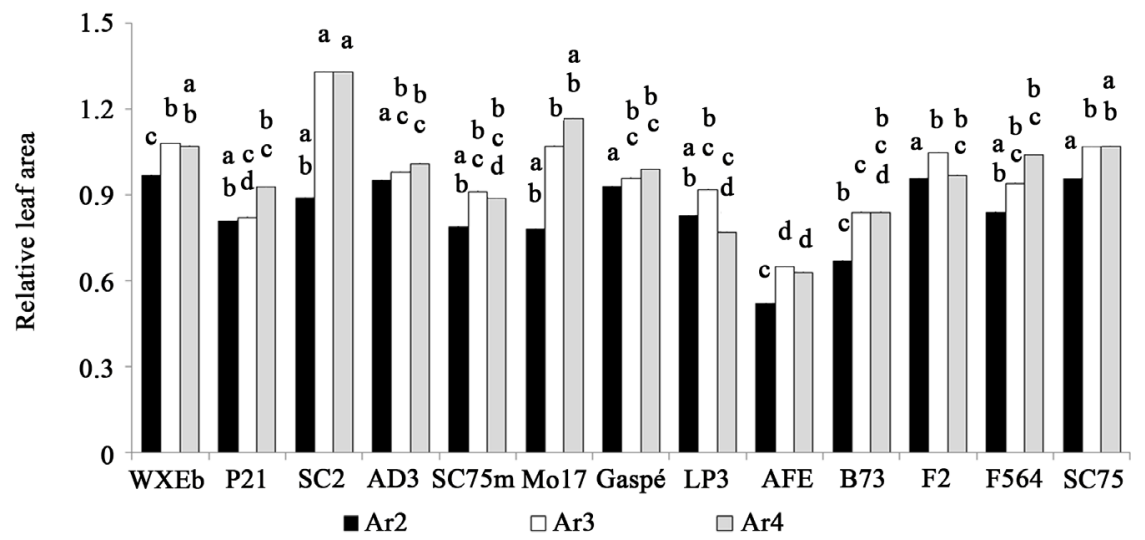

Figure 2. Means and typical error of the relative leaf area measured on the $4^{\text {th }}$ leaf (Area2, Area3 and Area4) recorded in maize genotypes stressed after four, six and eight days of exposure to $0 \mathrm{mM}$ and $100 \mathrm{mM}$ of $\mathrm{NaCl}$ doses. LSD test $(p<0.05)$ was separately calculated for each moment. 
Table 2. Variance analysis of maize genotypes exposed during two weeks to $0 \mathrm{mM}$ (control) and $100 \mathrm{mM}$ of $\mathrm{NaCl}$ doses. Relative's values were calculated as the ratio between the value measured in salt and the value measured without salt, control. LR: length root; SDM: shoot dry mass; RDM: root dry mass; Ar2, Ar3 and Ar4: $4^{\text {th }}$ leaf area measured each two days.

\begin{tabular}{|c|c|c|c|c|c|c|c|}
\hline \multirow{2}{*}{ S. of Variation } & \multirow{2}{*}{ fd } & \multicolumn{6}{|c|}{ Mean Squares } \\
\hline & & LR & SDM & RDM & Ar2 & Ar3 & Ar4 \\
\hline Genotypes & 12 & $0.08^{* *}$ & $0.14^{* *}$ & $0.22^{* *}$ & $0.17^{* *}$ & $0.28^{* *}$ & $0.29^{* *}$ \\
\hline repetition & 11 & $0.01 \mathrm{~ns}$ & $0.04 \mathrm{~ns}$ & 0.05 & 0.05 & 0.04 & 0.03 \\
\hline Error & 97 & 0.01 & 0.06 & 0.05 & 0.05 & 0.04 & 0.03 \\
\hline
\end{tabular}

ns: non-significant; ${ }^{* * *}$ significant at $p<0.05$ and $p<0.01$, respectively.

Table 3. Two ways variance analysis of maize genotypes exposed during two week to $0 \mathrm{mM}$ (control) and $100 \mathrm{mM}$ of $\mathrm{NaCl}$ doses. Traits were measured in absolute values, LWL: leaf water loss; RWC: relative water content; IE: stability of membrane.

\begin{tabular}{ccccc}
\hline \multirow{2}{*}{ S. of Variation } & fd & \multicolumn{3}{c}{ Mean Squares } \\
\cline { 3 - 5 } & & LWL & RWC & IE \\
\hline Genotypes (G) & 12 & $61.28^{*}$ & 32.08 & $74.26^{* *}$ \\
Treatment (T) & 1 & $412.95^{* *}$ & 121 & $1016.25^{* *}$ \\
G $\times$ T & 12 & $77.28^{* *}$ & 20.61 & 64.03 \\
Error & 55 & 27.5 & 33.82 & 27.33 \\
\hline
\end{tabular}

ns: non-significant; ${ }^{* * * *}$ significant at $p=0.05$ and $p=0.01$, respectively.

( $8^{\text {th }}$ day). AFE held a significantly lower relative growth rate at all moments. LP3 genotype showed a good rate of growth in the first measurements however it was that had greater loss of growth in the last measurement (Figure 2).

The salinity affects the rate of growth rather than growth time [7]. It means that the emergence of the $6^{\text {th }}$ leaf would delay due to salinity. It can be seen in Figure 3 where the lines: Mo17, WXEb, SC75m, P21, LP3, and AFE delayed the appearance of the $6^{\text {th }}$ leaf and this causes a significant reduction in growth associated with saline treatment. Besides, among these genotypes LP3 showed significant differences in growth for the treatments with and without salt.

Manhattan distance coefficient and UPGMA linked method grouped genotypes in 4 clusters (Figure 4) with a cophenetic correlation coefficient of 0.77 , which would indicate an acceptable adjustment between the dendrogram and the true distances between genotypes. A LSD Test (using a significance level of $p<0.05$ ) was performed to prove significant differences among the obtained clusters. Clusters didn't show significant differences for IE and LR traits. Group I included genotypes higher values for Ar3 (mean: 1.05), Ar4 (mean: 1.085), SDM (mean: 1.08) and RDM (mean: 1.12). Contrary Group IV, conformed to AFE inbred line alone showed the lowest means, whatever It had no differences with cluster I and III for RDM and LWL, respectively. Thus, Clusters II and III showed mid values and non-significant differences with cluster I for Ar2, Ar3, Ar4 nor with the cluster IV for SDM and RDM.

Principal Component method identified the first three components which explained the $77.6 \%$ of the variability present in the original variables. The genotypes were classified as the dendrogram. PC1 explained the $42.4 \%$ of the variability with high and positive correlations with Ar4, SDM, Ar3, Ar2 and PC2 explained the $18.7 \%$ of the total variability and showed moderate and positive correlations with RWC, LR and LWL. PC3 explained 16\% of the variability with positive correlations with IE and RDM but negative correlation with RWC (Figure 5).

The tolerance index selected two extremely genotypes, SC2 and AFE, which presented values of 8.67 y 6.7, respectively (Table 4).

\section{Discussion}

Osmotic stress causes a rapid inhibition in the expansion of the young leaves and reduced stomatal conductance 

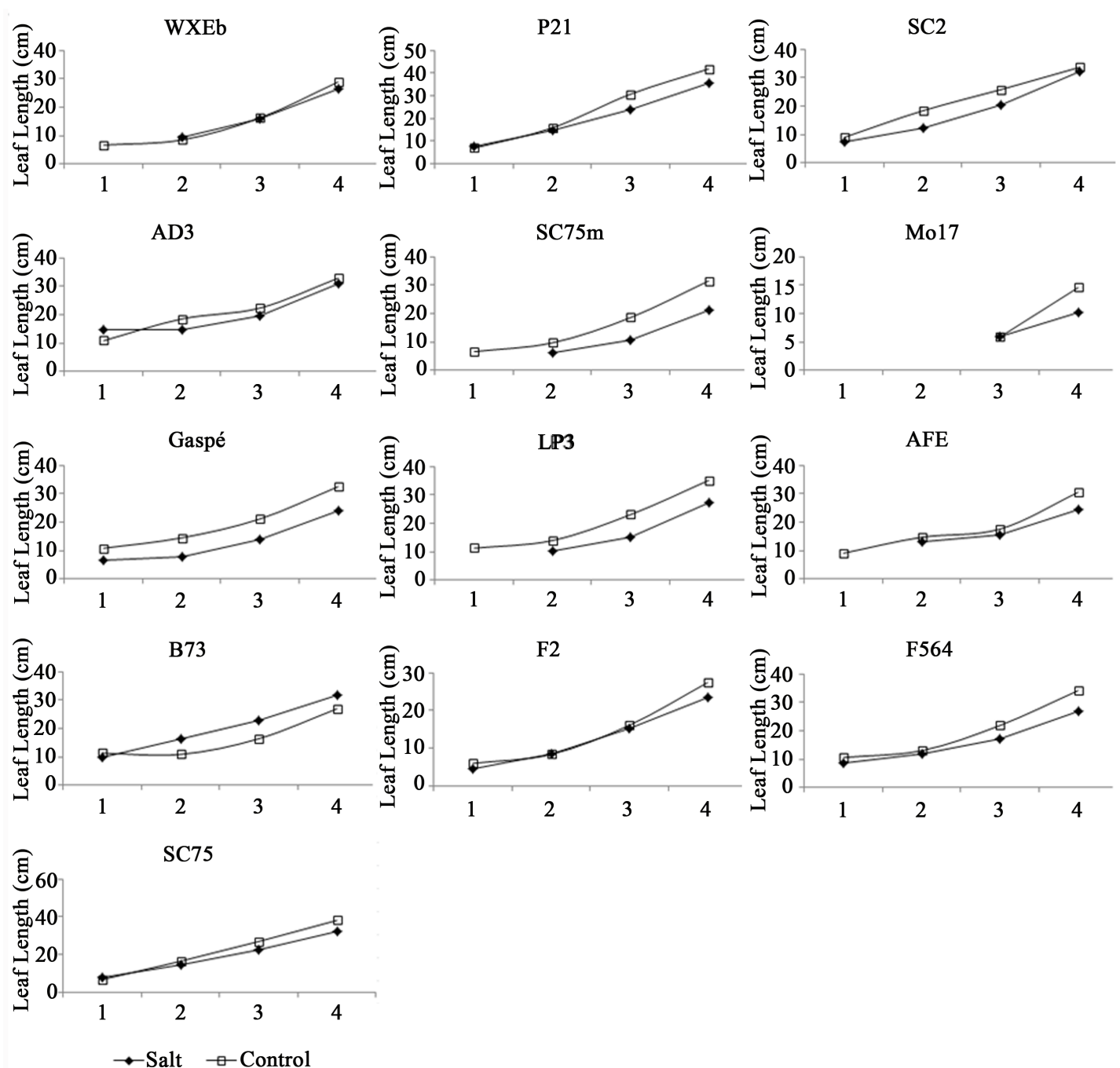

Figure 3. $6^{\text {th }}$ leaf length for each maize genotype considering Control $(0 \mathrm{mM} \mathrm{NaCl})$ and Saline $(100 \mathrm{mM} \mathrm{NaCl})$ treatment. The leaf length was measured each two days $\left(1,2,3\right.$ and 4 represent the $6^{\text {th }}, 8^{\text {th }}, 10^{\text {th }}$ and $12^{\text {th }}$ day from the complete salinization, respectively). Each value is the mean of 12 replicates.

Table 4. Tolerance index for 13 inbreed lines sorted in descending order.

\begin{tabular}{cc}
\hline Genotypes & Tolerance index \\
\hline SC2 & 8.67 \\
AD3 & 8.27 \\
WXEb & 8.27 \\
Gaspe & 8.06 \\
Sc75 & 8.02 \\
F564 & 7.81 \\
P21 & 7.79 \\
F2 & 7.76 \\
Mo17 & 7.68 \\
LP3 & 7.10 \\
Sc75m & 7.01 \\
B73 & 6.96 \\
AFE & 6.70 \\
\hline
\end{tabular}




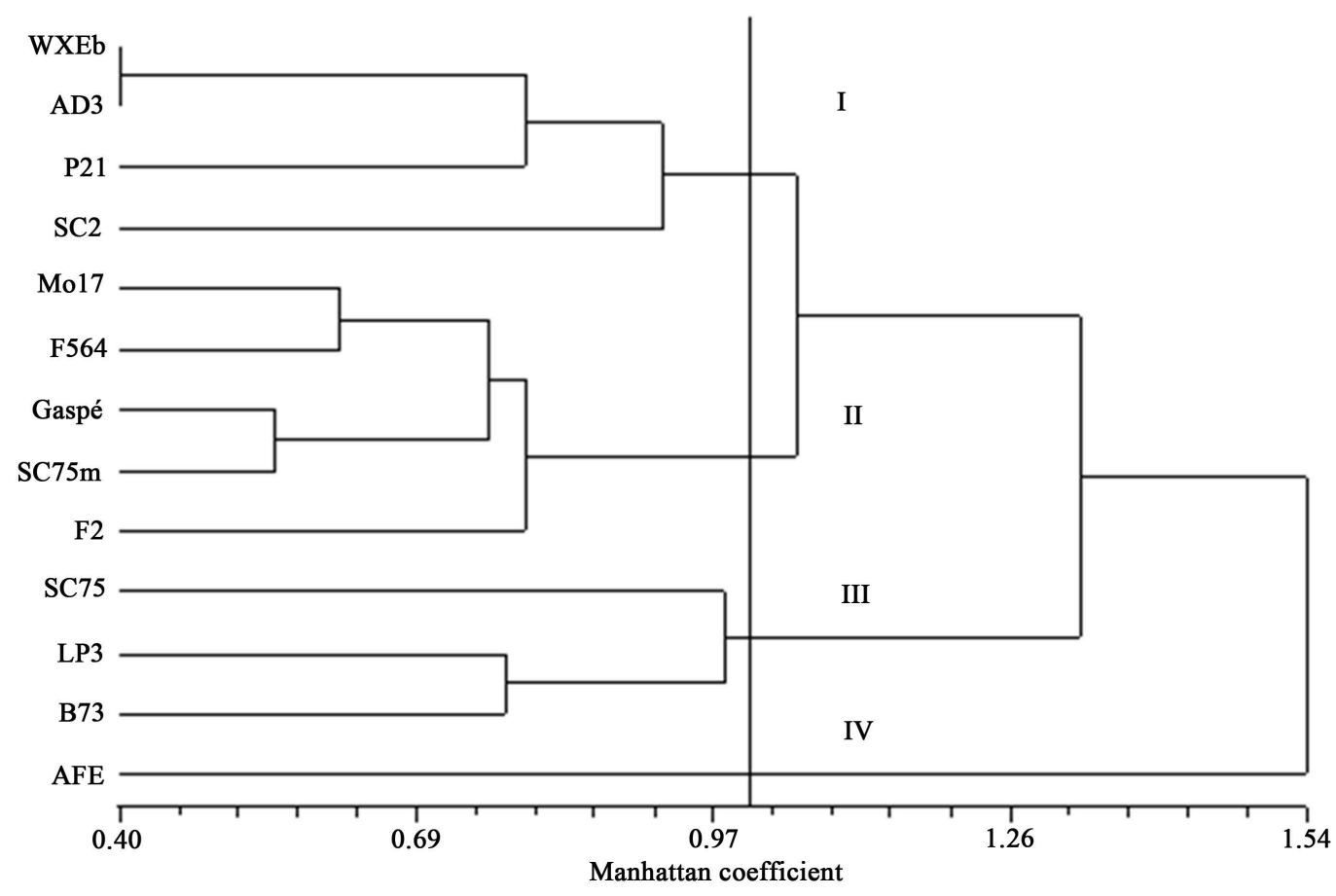

Figure 4. Classification of maize genotypes growing in salt conditions (100 $\mathrm{mM} \mathrm{NaCl})$ : Dendrogram build with the Manhattan distance y UPGMA and using absolute means values of the 9 traits: length root; shoot dry mass; root dry mass; Ar2, Ar3 and Ar4: $4^{\text {th }}$ leaf area measured each two days; relative water content; leaf water loss; stability of membrane. Cophenetic Correlation Coefficient: 0.77.

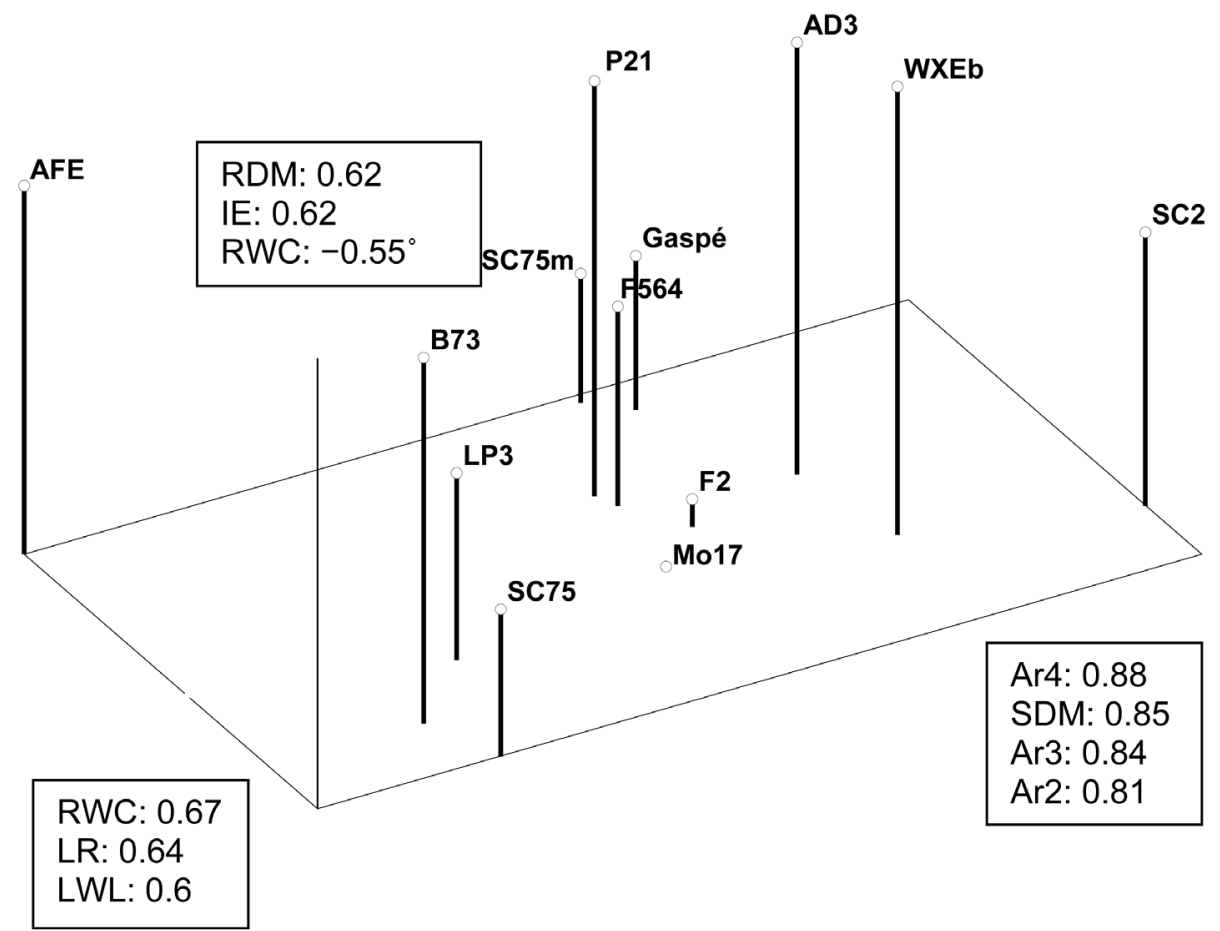

Figure 5. Maize genotype exposed during two weeks $100 \mathrm{mM}$ of $\mathrm{NaCl}$ grouped using Principal Component Analysis. Traits were: LR: length root; SDM: shoot dry mass; RDM: root dry mass; Ar2, Ar3 and Ar4: $4^{\text {th }}$ leaf area. RWC: relative water content; LWL: leaf water loss; IE: stability of membrane. Three dimensional graphics expressed the $77.6 \%$ of total variability. Numbers inside the squared represents eigenvector's coefficients for each trait. 
of mature leaves. Evaluation of the $4^{\text {th }}$ leaf growth and the time of emergence and final development of the $6^{\text {th }}$, were used to measure osmotic stress. It can be assumed that the reduction in growth after 7 days of exposure in salt just might be more osmotic effects that the accumulation of $\mathrm{Na}^{+}$(ionic effect). The decrease in leaf area could be considered as the first response of glycophytes plants in salinity. This behavior would be a way of avoiding excessive water loss by transpiration, although on the other hand, the reduction in leaf area could have adverse effects on gas exchange and photosynthesis [6] [27].

The genotypes showed significant differences in reducing the growth of the $4^{\text {th }}$ leaf [12] [17] [28]. The different degrees of reduction could be signaling the presence of genetic variability among the genotypes for osmotic stress associated with salinity. Also it could be seen, that the $4^{\text {th }}$ leaf elongation rate presented differences between genotypes. The genotypes: WXEb, LP3, AFE, SC75m and F2 did not show exponential growth in the last measurement. It appears that growth stagnates or is lower than that observed in controls. This would be pointing out that these genotypes in salinity have a greater reduction in growth and consequently would be sensitive to the salinity. In addition, the delay in the appearance of the 6th could be another evidence of their sensitive behavior to salt [6].

Salinity also produced significant reductions among genotypes for SDM and RDM; in consequence the most affected inbreed would be susceptible to salinity while the tolerant ones would suffer a smaller reduction [12] [17] [29]. Tolerance tests of short-term guarantee that the responses observed are due largely to the osmotic stress, because still there are not sufficient accumulation of $\mathrm{Na}^{+}$as to produce damage [5] [11].

The decrease in the rate of growth of leaves, after salt exposure may be due to osmotic effects caused by cumulative salts surrounding the roots. This determines a loss of water and turgidity of the cells. In this regard, assessments of the plant water status could help in the selection of the genotypes. For this purpose, LWL and RWC can be very useful. LWL is an indicator of "residual transpiration" that are associated with the loss of water through the cuticle tissue with a minimum stomatal opening [30]. The RWC is strongly related to the cell volume and can reflect the leaf water balance and the transpiration rate. One of the first symptoms of the deficiency of water in the tissues is the decrease of the RWC. However, there was no significant difference among the genotypes for the character [31]; instead, [32] detected differences. Due to this ambiguous behavior, RWC not be a reliable trait to identify tolerant genotypes.

The loss of the integrity of the cell membranes and the increase of permeability are the first damage caused by salt stress. Therefore, the cellular ability to control the movement of ions would give an idea of the degree of tissue damage. The character IE was used successfully in the selection of salinity tolerance in wheat [33] [34]. Changes in the composition and structure of the cell membrane by salinity stress would show differences between tolerant and sensitive species. Our results also showed differences in the behavior of the genotypes for IE [22].

The information obtained from the application of Principal component analysis, cluster analysis and indexes of tolerance allowed the identification of genotypes according to their behavior as tolerant or susceptible. The PCA identified 4 groups. The genotypes SC2, AD3, WXEb and P21 were located in the first group. This group included individuals who have a great development of the stem (high SDM and Ar2, Ar3 and Ar4) and root (high RDM). However, these genotypes showed differences in the water status. In this group highlighted the genotype SC2 that showed the greatest shoot growth; although its water content (RWC) was low which would indicate that used efficiently absorbed water. The second group was integrated by genotypes Gaspé, SC75m, F564, F2 and Mo17, which were characterized for showing a moderate growth of shoot and root, although differ in water content. The third group was composed by B73, LP3 and SC75 which presented a strong reduction of the shoot growth and water content. In the last group ranked the AFE genotype that presented lower shoot growth but higher root length, and a greater loss of water by cuticular transpiration and high damage to cell membranes (IE higher) (Figure 4).

Tolerance index allowed to classify genotypes, thus SC2 and AD3 lines were which reached highest value of the index and therefore would be tolerant lines, while AF3 and LP3 had a low index and were seen as sensible.

\section{Conclusions}

We studied the effects of salinity on growth and water economy traits in seedlings of maize, to explore the presence of genetic variability for osmotic tolerance mechanism; with the purpose of identifying genotypes of contrasting behavior useful for gene effects' studies and for breeding programs. We employed three different methodologies for the screening: Cluster Analysis, Principal Component Analysis and a Tolerance Index. Whi- 
chever the methodology used for genotypes classification had similar results and therefore they could indistinctly be used as a selection tool.

Thus, the selected genotypes as tolerant were SC2 and AD3 while AFE and LP3 were identified as susceptible. These inbreed lines with contrasting behavior could be used as putative parents to obtain segregating populations (Fn or RILS) capable of being applied to genetic studies such as the identification of quantitative traits loci (QTLs analysis) associated to osmotic stress.

\section{References}

[1] FAOSTAT, 2008. http://www.fao.org/corp/statistics/es/

[2] Khan, M.H. and Panda, S.K. (2008) Alterations in Root Lipid Peroxidation and Antioxidative Responses in Two Rice Cultivars under NaCl-Salinity Stress. Acta Physiologiae Plantarum, 30, 89-91

[3] Munns, R. (2002) Comparative Physiology of Salt and Water Stress. Plant, Cell \& Environment, 25, 239-250. http://dx.doi.org/10.1046/j.0016-8025.2001.00808.x

[4] Munns, R. and James, R.A. (2003) Screening Methods for Salinity Tolerance: A Case Study with Tetraploid Wheat. Plant and Soil, 253, 201-218. http://dx.doi.org/10.1023/A:1024553303144

[5] Munns, R. (1993) Physiological Processes Limiting Plant Growth in Saline Soils: Some Dogmas and Hypotheses. Plant and Cell Environment, 16, 15-24. http://dx.doi.org/10.1111/j.1365-3040.1993.tb00840.x

[6] Munns, R. and Tester, M. (2008) Mechanisms of Salinity Tolerance. Annual Review of Plant Biology, 59, 651-681. http://dx.doi.org/10.1146/annurev.arplant.59.032607.092911

[7] Yaseen, B.T., Abu-Al Basal, M.A. and Alhadi, F.A. (2010) An Analysis of Leaf Growth under Osmotic Stress. Journal of Plant Sciences, 5, 391-401. http://dx.doi.org/10.3923/jps.2010.391.401

[8] Tester, M. and Davenport, R. (2003) $\mathrm{Na}^{+}$Tolerance and $\mathrm{Na}^{+}$Transport in Higher Plants. Annals of Botany , 91, 503527. http://dx.doi.org/10.1093/aob/mcg058

[9] Munns, R., James, R.A. and Lauchli, A. (2006) Approaches to Increasing the Salt Tolerance of Wheat and Other Cereals. Journal of Experimental Botany, 57, 1025-1043. http://dx.doi.org/10.1093/jxb/erj100

[10] Blaha, G., Stelzl, U., Spahn, C.M., Agrawal, R.K., Frank, J. and Nierhaus, K.H. (2000) Preparation of Functional Ribosomal Complexes and Effect of Buffer Conditions on tRNA Positions Observed by Cryoelectron Microscopy. Methods in Enzymology, 317, 292-306. http://dx.doi.org/10.1016/S0076-6879(00)17021-1

[11] Sümer, A., Zörb, C., Yan, F. and Schubert, S. (2004) Evidence of Sodium Toxicity for the Vegetative Growth of Maize (Zea mays L.) during the First Phase of Salt Stress. Journal of Applied Botany, 78, 135-139.

[12] Zhao, K.-F., Song, J., Fan, H., Zhou, S. and Zhao, M. (2010) Growth Response to Ionic and Osmotic Stress of NaCl in Salt-Tolerant and Salt-Sensitive Maize. Journal of Integrative Plant Biology, 52, 468-475. http://dx.doi.org/10.1111/j.1744-7909.2010.00947.x

[13] Byrt, C.S., Platten, J., Spielmayer, W., James, R.A., Lagudah, E., Dennis, E., Tester, M. and Munns, R. (2007) HKT1; 5-Like Cation Transporters Linked to $\mathrm{Na}^{+}$Exclusion Loci in Wheat, Nax2 and Kna1. Plant Phisiology, 143, 19181928. http://dx.doi.org/10.1104/pp.106.093476

[14] Maas, E.V. and Hoffman, G.J. (1983) Salt Sensitivity of Corn at Various Growth Stages. California Agriculture, 37, 14-15. http://dx.doi.org/10.1007/bf00285556

[15] Drew, M.C. and Lauchli, A. (1985) Oxygen-Dependent Exclusion of Sodium Ions from Shoots by Roots of Zea mays L.(cv. Pioneer 3906) in Relation to Salinity Damage. Plant Phisiology, 79, 171-176.

[16] Azevedo Neto, A., Tarquinio Prisco, J., Enéas-Filho, J., Medeiros, J. and Gomes-Filho, E. (2005) Effects of Salt Stress on Plant Growth, Stomatal Response and Solute Accumulation of Different Maize Genotypes. Journal of Plant Physiology, 162, 1114-1122.

[17] De Costa, W., Zörb, C., Hartung, W. and Schubert, S. (2007) Salt Resistance Is Determined by Osmotic Adjustment and Abscisic Acid in Newly Developed Maize Hybrids in the First Phase of Salt Stress. Physiologia Plantarum, 131, 311-321. http://dx.doi.org/10.1111/j.1399-3054.2007.00962.x

[18] Cicek, N. and Cakirlar, H. (2002) The Effect of Salinity on Some Physiological Parameters in Two Maize Cultivars. Bulgarian Journal of Plant Physiology, 28, 66-74.

[19] Zhang, H.J. and Brandle, R. (1997) Leaf Area Development of Corn as Affected by Wind Break Shelter. Crop Science, 37, 1253-1256. http://dx.doi.org/10.2135/cropsci1997.0011183X003700040037x

[20] Mata, C.G. and Lamattina, L. (2001) Nitric Oxide Induces Stomatal Closure and Enhances the Adaptative Plant Responses against Drought Stress. Plant Physiology, 126, 1196-1204. http://dx.doi.org/10.1104/pp.126.3.1196

[21] Xing, H., Tan, L., An, L., Zhao, Z., Wang, S. and Zhang, C. (2004) Evidence for the Involvement of Nitric Oxide and 
Reactive Oxygen Species in Osmotic Stress. Tolerance of Wheat Seedling: Inverse Correlation between Leaf Abscicic Acid Accumulation and Leaf Water Loss. Plant Growth Regulation, 42, 61-68. http://dx.doi.org/10.1023/B:GROW.0000014894.48683.1b

[22] Mansour, M.M., Salama, K.H., Ali, F.Z. and Abou Hasid, A.F. (2005) Cell and Plant Response to NaCl in Zea mays L. Cultivars Differing in Salt Tolerance. Genetic Applied Plant Physiology, 31, 29-41.

[23] Sokal, R.R. and Rohlf, F.J. (1995) Biometry: The Principals and Practice of Statistics in Biological Research. W.H. Freeman and Company, San Francisco.

[24] Sneath, P.H.A. and Sokal, R.R. (1973) Numerical Taxonomy: The Principles and Practice of Numerical Classification. Freeman and Co., San Francisco.

[25] Cain, A.J. and Harrison, G.A. (1958) An Analysis of the Taxonomist's Judgement of Affinity. Proceeding of the Zoological Society, 131, 85-98. http://dx.doi.org/10.1111/j.1096-3642.1958.tb00634.x

[26] Rohlf, F.J. (1998) NTSyS-p.c. Numerical Taxonomy and Multivariate Analysis System (Version 2.0). Exeter Software Publishers Ltd., Setauket.

[27] Rajendran, K., Tester, M. and Roy, S. (2009) Quantifying the Three Main Components of Salinity Tolerance in Cereals. Plant, Cell and Environment, 32, 237-249. http://dx.doi.org/10.1111/j.1365-3040.2008.01916.X

[28] Abreu, C., Prisco, J., Nogueira, A., Bezerra, M., Lacerda, C. and Gomes-Filho, E. (2008) Physiological and Biochemical Changes Occurring in Dwarf-Cashew Seedlings Subjected to Salt Stress. Brazilian Journal of Plant Physiology, 20 105-118. http://dx.doi.org/10.1590/S1677-04202008000200003

[29] Pitann, B., Schubert, S. and Mühling, K. (2009) Decline in Leaf Growth under Salt Stress Is Due to an Inhibition of $\mathrm{H}^{+}$ Pumping Activity and Increase in Apoplastic pH of Maize Leaves. Journal Plant Nutrition and Soil Sciences, 172, 535-543. http://dx.doi.org/10.1002/jpln.200800349

[30] Bilgin, O., Baser, I., Korkut, K., Balkan, A. and Saglam, N. (2008) The Impacts on Seedling Root Growth of Water and Salinity Stress in Maize (Zea mays indentata Sturt). Bulgarian Journal of Agricultural Science, 14, 313-320.

[31] Valentovič, P., Luxová, M., Kolarovič, L. and Gašparíková, O. (2006) Effect of Osmotic Stress on Compatible Solutes Content, Membrane Stability and Water Relations in Two Maize Cultivars. Plant Soil Environment, 52, $186-191$.

[32] Abu-Al-Basal, M. and Yassee, B.T. (2009) Changes in Growth Variables and Potassium Content in Leaves of Black Barley in Response to NaCl. Brazilian Journal of Plant Physiology, 21, 261-269. http://dx.doi.org/10.1590/S1677-04202009000400002

[33] Farooq, S. and Azam, F. (2006) The Use of Cell Membrane Stability (CMS) Technique to Screen for Salt Tolerant Wheat Varieties. Journal of Plant Physiology, 163, 629-637. http://dx.doi.org/10.1016/j.jplph.2005.06.006

[34] Sairam, R., Rao, K. and Srivastava, G. (2002) Differential Response of Wheat Genotypes to Long Term Salinity Stress in Relation to Oxidative Stress, Antioxidant Activity and Osmolyte Concentration. Plant Science, 163, 1037-1046. http://dx.doi.org/10.1016/S0168-9452(02)00278-9 